\title{
Bimodal Fluorescence and Magnetic Resonance Imaging Using Water-Soluble Hexagonal $\mathrm{NaYF}_{4}: \mathrm{Ce}, \mathrm{Tb}, \mathrm{Gd}$ Nanocrystals
}

\author{
Wen Ting Ren,, 2 Liang Bo Liang, ${ }^{1}$ Fei Qi, ${ }^{1}$ Zheng Bo Sun, ${ }^{3}$ Zhi Yong Yang, ${ }^{1,2}$ Xiao Qi Huang, \\ Qi Zhu Wu, ${ }^{2}$ Hong Yan Zhu, ${ }^{4}$ Xue Feng Yu, ${ }^{1,3}$ Hong Quan, ${ }^{1}$ and Qi Yong Gong ${ }^{2}$ \\ ${ }^{1}$ Department of Physics, Key Laboratory of Artificial Micro- and Nano-Structures of Ministry of Education and School of Physics and \\ Technology, Wuhan University, Wuhan 430072, China \\ ${ }^{2}$ Huaxi MR Research Center (HMRRC), Department of Radiology, West China Hospital of Sichuan University, \\ Chengdu 610041, China \\ ${ }^{3}$ State Key Laboratory of Virology, College of Life Sciences, Wuhan University, Wuhan 430072, China \\ ${ }^{4}$ Laboratory of Stem Cell Biology, State Key Laboratory of the Biotherapy, West China Hospital of Sichuan University, \\ Chengdu 610041, China
}

Correspondence should be addressed to Xue Feng Yu, yxf@whu.edu.cn and Hong Quan, csp6606@sina.com

Received 12 July 2011; Accepted 13 September 2011

Academic Editor: Anukorn Phuruangrat

Copyright ( $) 2011$ Wen Ting Ren et al. This is an open access article distributed under the Creative Commons Attribution License, which permits unrestricted use, distribution, and reproduction in any medium, provided the original work is properly cited.

\begin{abstract}
The present study explored the feasibility of using hexagonal-phase $\mathrm{NaYF}_{4}$ :Ce,Tb,Gd nanocrystals as bimodal probes for fluorescence and magnetic resonance (MR) imaging. Using a facile and user-friendly strategy, the $\mathrm{NaYF}_{4}: \mathrm{Ce}, \mathrm{Tb}, \mathrm{Gd}$ nanocrystals were synthesized with good water dispensability, high quantum yield (26\%), and decent MR $T_{1}$ relaxivity $\left(r_{1}=2.87 \mathrm{mM}^{-1} \mathrm{~s}^{-1}\right)$. The $\mathrm{NaYF}_{4}: \mathrm{Ce}, \mathrm{Tb}, \mathrm{Gd}$ NCs conjugated by folic acid presented great efficiency in fluorescence imaging of C6 glioma cells in vitro. Meanwhile, in in vivo MR experiments on rats, the $\mathrm{NaYF}_{4}: \mathrm{Ce}, \mathrm{Tb}, \mathrm{Gd} N \mathrm{NC}$ also significantly increased $T_{1}$ signal in the liver, spleen, and kidney even with a low probe dose. The proposed $\mathrm{NaYF}_{4}: \mathrm{Ce}, \mathrm{Tb}, \mathrm{Gd}$ nanoprobes hold promise for simultaneous bimodal fluorescence and MR bioimaging.
\end{abstract}

\section{Introduction}

Multimodal bioimaging, which shows advantages over traditional single-imaging modality, has been regarded as a new research frontier in biological and medical sciences [1-3]. Among various imaging techniques, fluorescence imaging provides the highest sensitivity and spatial resolution for in vitro bioimaging. However, fluorescence imaging suffers from lacking of detailed anatomical and physiological information in vivo. Magnetic resonance imaging (MRI), a noninvasive diagnostic method in clinic, offers excellent anatomical and functional information for in vivo bioimaging, but it is limited due to the poor sensitivity and resolution for cell imaging [3-5]. Therefore, a probe with the combination of fluorescence and MR imaging could bridge gaps in resolution and depth of bioimaging and would provide a useful diagnostic tool for both in vitro and in vivo studies [4, 69]. By virtue of this bimodal combination, some applica- tions have been exploited such as biological marking, photodynamic therapeutic intervention, tumors targeting, and drug delivering [10-12]. Realization of such bimodal probes with high performance and good biocompatibility has aroused great research interests $[13,14]$, though it is still a great challenge now.

In recent years, nanocrystals (NCs) of rare-earth (RE) compounds have been proposed to be a promising new class of biological probes due to their unique optical and chemical features [15-18]. Ascribed to their special electron configuration, lanthanide ions (such as $\mathrm{Tb}^{3+}, \mathrm{Eu}^{3+}, \mathrm{Er}^{3+}$, and $\mathrm{Nd}^{3+}$ ) exhibit sharp fluorescent emissions with long lifetime, superior photostability, and high resistance to photobleaching and photoblinking $[19,20]$. In addition, other lanthanide ions including $\mathrm{Gd}^{3+}$ possess a large number of unpaired electrons, which could become a paramagnetic relaxation agent with positive contrast enhancement in $T_{1}$-weighted MRI [21]. Among various RE compounds, hexagonal-phase 
$\mathrm{NaYF}_{4}$ has attracted increasing attention as a matrix for lanthanide ions, because it is considered to be one of the most efficient host materials for supporting fluorescence of lanthanide ions [22-24]. What is more, at present high-quality NaYF4 nanocrystals have been synthesized by a user-friendly method [25], which makes this material more attractive on bioimaging applications. On the road to realize bimodal imaging, incorporation of fluorescence $\mathrm{RE}^{3+}$ ions and $\mathrm{Gd}^{3+}$ ions in $\mathrm{NaYF}_{4}$ nanocrystals have been demonstrated as an efficient route [4]. Nevertheless, the combination of the fluorescence and MR bioimaging for both in vitro and in vivo studies has rarely been studied.

In the present work, a bimodal nanoprobe was synthesized by codoping $\mathrm{Ce}^{3+}, \mathrm{Tb}^{3+}$, and $\mathrm{Gd}^{3+}$ ions in $\mathrm{NaYF}_{4}$. The synthesized hexagonal-phase $\mathrm{NaYF}_{4}: \mathrm{Ce}, \mathrm{Tb}, \mathrm{Gd} \mathrm{NCs}$ exhibit good water solubility, low cytotoxicity and demonstrate both high fluorescence efficiency (26\%) and high MR enhancement (58\%). Using the $\mathrm{NaYF}_{4}: \mathrm{Ce}, \mathrm{Tb}, \mathrm{Gd} \mathrm{NCs}$ as probes, we successfully demonstrate fluorescence imaging of C6 glioma cells in vitro and MR imaging for liver, spleen, and kidney of rat in vivo. These results provide an insight into this novel type of biological agent in multimodal bioimaging.

\section{Experimental Section}

2.1. Reagents and Materials. Branched polyethylenimine (PEI, Mw = 10000), folic acid, 1-ethyl-3-(3-dimethylaminopropyl)-carbodiimide hydrochloride (EDC), dimethyl sulfoxide (DMSO), $\mathrm{NaCl}, \mathrm{RECl}_{3} \cdot 6 \mathrm{H}_{2} \mathrm{O}(\mathrm{RE}=\mathrm{Y}, \mathrm{Gd}, \mathrm{Ce}, \mathrm{Tb})$, and $\mathrm{NH}_{4} \mathrm{~F}$ were purchased from Sigma-Aldrich without further purification. PEI stock solution (5 wt \%) was prepared by dissolving PEI in ultrapure water. $\mathrm{NaCl}, \mathrm{RECl}_{3}$ stock solutions $(0.5 \mathrm{M})$ and $\mathrm{NH}_{4} \mathrm{~F}$ stock solution $(1 \mathrm{M})$ were prepared in ultrapure water, respectively.

2.2. Synthesis. In a typical procedure to synthesize PEI-coated $\mathrm{NaYF}_{4}: 10 \% \mathrm{Ce}, 5 \% \mathrm{~Tb}, 10 \% \mathrm{Gd}, 5 \mathrm{~mL}$ of PEI solution, $1.0 \mathrm{~mL}$ of $\mathrm{NaCl}, 0.1 \mathrm{~mL}$ of $\mathrm{GdCl}_{3}, 0.1 \mathrm{~mL}$ of $\mathrm{CeCl}_{3}$ and $0.05 \mathrm{~mL}$ of $\mathrm{TbCl}_{3}$, were added to $15 \mathrm{~mL}$ ethanol in sequence. After 5 min vigorous agitation, a stoichiometric amount of $\mathrm{NH}_{4} \mathrm{~F}$ was charged. After another 15 min stirring, the resulting solution was transferred to a $50 \mathrm{~mL}$ Teflon-lined autoclave and eventually heated at $200^{\circ} \mathrm{C}$ for $3 \mathrm{~h}$. After naturally cooling down, the product was collected by centrifugation, washed with ethanol and ultrapure water for several times, then dissolved in $20 \mathrm{~mL}$ of $\mathrm{GdCl}_{3}(0.1 \mathrm{M})$ and stirred for $3 \mathrm{~h}$. Finally, the sample was obtained by centrifugation, washed with ethanol and ultrapure water several times, and dried in vacuum.

2.3. Characterization. The X-ray powder diffraction (XRD) analysis was carried out on a Bruker D8 ADVANCE X-ray diffractometer with $\mathrm{Cu} \mathrm{K} \alpha 1$ irradiation $(\lambda=1.5406 \AA)$. The transmission electron microscopy (TEM) measurements were performed with a JEOL 2010 HT microscope (operated at $200 \mathrm{kV})$.

2.4. In Vitro Cell Imaging. Folic acid $(75 \mathrm{mg})$ and EDC $(180 \mathrm{mg})$ were dissolved in $30 \mathrm{~mL}$ of DMSO. After a halfhour mild agitation, $3 \mathrm{~mL}$ of DMSO containing $15 \mathrm{mg}$
$\mathrm{NaYF}_{4}$ :Ce,Tb,Gd NCs was slowly added. The mixture was stirred at room temperature for $4 \mathrm{~h}$. The products were collected using centrifugation, washed with DMSO and ultrapure water several times, and then dispersed in $3 \mathrm{~mL}$ of ultrapure water.

Prior to cell fluorescence imaging, live rat C6 glioma cells (obtained from the Cell Bank of the Chinese Academy of Sciences (Shanghai, China)) were incubated with folic acid conjugated by $\mathrm{NaYF}_{4}: \mathrm{Ce}, \mathrm{Tb}, \mathrm{Gd} \mathrm{NCs}$ at the concentration of $1000 \mu \mathrm{g} / \mathrm{mL}$ at $37^{\circ} \mathrm{C}$ and $5 \% \mathrm{CO}_{2}$ for $12 \mathrm{~h}$. The living cell fluorescence was observed by an inverted fluorescence microscope (Olympus IX 70), coupled with a digital camera (Nikon Coolpix 5400) and Image-pro Plus 5.0 image analysis software.

2.5. MRI Relaxation Measurements. In order to evaluate the effectiveness of $\mathrm{NaYF}_{4}: \mathrm{Ce}, \mathrm{Tb}, \mathrm{Gd} \mathrm{NCs}$ as an MRI contrast agent, the relaxation properties of $\mathrm{NaYF}_{4}: \mathrm{Ce}, \mathrm{Tb}, \mathrm{Gd} \mathrm{NCs}$ solutions were examined on a $3 \mathrm{~T} \mathrm{MR} \mathrm{scanner} \mathrm{(Siemens} \mathrm{trio}$ system, Huaxi MR Research Center, Chengdu, China) with a 12-channel phased array coil. Samples with concentration varying from $0.06 \mathrm{mg} / \mathrm{mL}$ to $1.67 \mathrm{mg} / \mathrm{mL}$ were prepared for $T_{1}$-weighted MR imaging by diluting them in deionized water. Deionized water was used as the reference sample. All the samples were scanned using standard Spin-Echo (SE) sequence $(\mathrm{TR}=500 \mathrm{~ms} ; \mathrm{TE}=9.4 \mathrm{~ms} ; \mathrm{FOV}=138 * 180$; matrix $=170 * 384$; slice thickness $=3 \mathrm{~mm}$; number of signal averages $=2$ ).

To further investigate the contrast effect of $\mathrm{NaYF}_{4}: \mathrm{Ce}, \mathrm{Tb}$, Gd NCs, specific relaxivity value $r_{1}$ was measured for each of the samples, respectively. Inversion recovery pulse sequence was used for the measurement of $T_{1}$ values $(\mathrm{TR} / \mathrm{TE}=$ $15 \mathrm{~ms} / 1.95 \mathrm{~ms} ; 10$ different inversion-recovery waiting delay values (TI) between $23 \mathrm{~ms}$ and $3 \mathrm{~s}$; FOV $=160 * 160$; matrix $=768 * 768$; slice thickness $=3 \mathrm{~mm}$ ). The signal intensity of each tube on MRI was measured by placing a circle region of interest (ROI) with voxel size of 200 pixels in the center of the tube. $T_{1}$ values of each tube were deduced from the following formula: $\mathrm{S}(\mathrm{TI})=\mathrm{S} 0 \times[1-$ $\left.2 \exp \left(-\mathrm{TI} / T_{1}\right)\right]$ by performing a nonlinear least-squares fit. A plot of $R_{1}$ versus $\mathrm{Gd}^{3+}$ concentration yielded a straight line with the slope defined as the $\mathrm{NaYF}_{4}$ :Ce,Tb,Gd NCs $T_{1}$ relaxivity value $r_{1}$.

2.6. In Vivo MRI Studies. In vivo experiments were performed on white Sprague-Dawley (SD) rats $(3-60 \mathrm{~g})$ under authorization of the Animal and Human Ethics Committee of the West China Hospital at Sichuan University. MR scanning was performed on a Philips Achieva 3.0 T system with a phased array coil for rat (Shanghai Chenguang Medical Technologies Co., Ltd). After intraperitoneal injection of $10 \%$ chloral hydrate $0.4 \mathrm{~mL}$, the rat was placed pronely in the MR system with its abdomen at the center of the coil. The $\mathrm{NaYF}_{4}$ :Ce,Tb,Gd NCs solution was injected intravenously, and dynamic MRI 3D images $(\mathrm{TR} / \mathrm{TE}=18 \mathrm{~ms} / 8 \mathrm{~ms}$, matrix $=148 * 124$, slices $=30$ ) were obtained before and $0.67,1.5$, $3,9,24$, and $48 \mathrm{~h}$ after the administration of contrast agent for each animal (maintained at normal body temperature). Signal intensity was measured at the each time point by using 


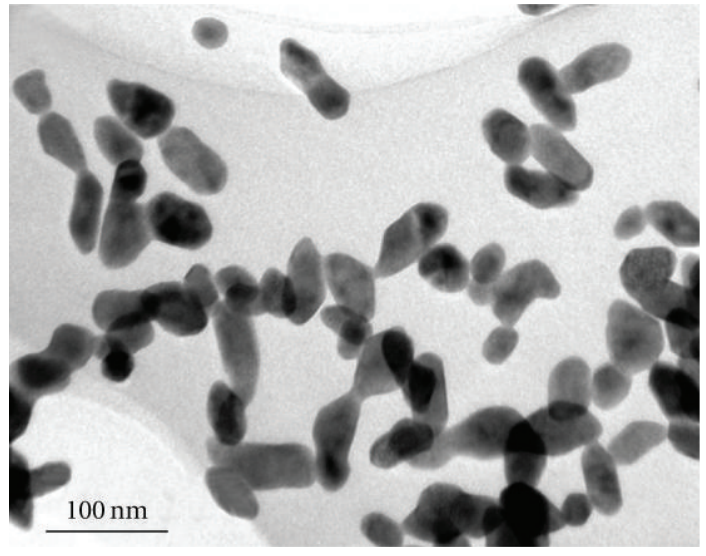

(a)

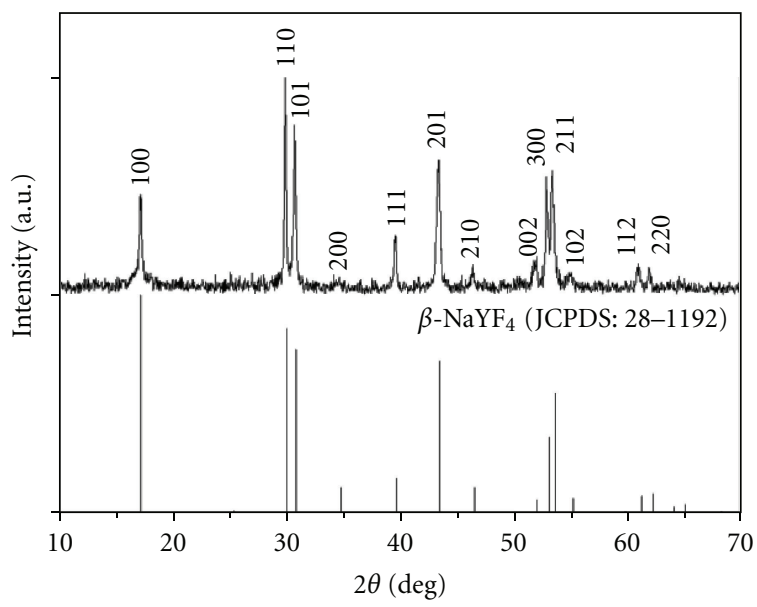

(b)

FIgURe 1: (a) TEM image; (b) XRD pattern.

Siemens Syngo software, and the relative signal intensity changes were plotted against time.

\section{Results and Discussion}

The characterization of the PEI-coated $\mathrm{NaYF}_{4}: \mathrm{Ce}, \mathrm{Tb}, \mathrm{Gd}$ NCs (Y:Ce:Tb:Gd = 75:10:5:10) was demonstrated in Figure 1. As indicated in Figure 1(a), the products took on a rod-like shape with an average diameter of approximately $30 \mathrm{~nm}$. The XRD pattern in Figure 1(b) exhibited that peak positions were in good accordance with the data in the JCPDS standard card (28-1192) for hexagonal $\mathrm{NaYF}_{4}$ crystals. It was known that the $\mathrm{NaYF}_{4}$ nanocrystal in hexagonalphase had been regarded as one of the most efficient host materials for RE fluorescence [22-24].

The surface properties of the products were exhibited by using FTIR spectrum. As shown in Figure 2, two strong bands ( 3428 and $1635 \mathrm{~cm}^{-1}$ ), originating from $\mathrm{O}-\mathrm{H}$ stretching and $\mathrm{H}-\mathrm{O}-\mathrm{H}$ bending modes of vibration, render the NCs water soluble. Furthermore, the absorption peaks from internal vibration of amide bonds $\left(1382 \mathrm{~cm}^{-1}\right)$ and $\mathrm{CH}_{2}$ stretching vibrations (2863 and $2927 \mathrm{~cm}^{-1}$ ) demonstrated the presence of PEI on the particle surface. The PEI-coated NCs could give a direct conjugation of biomolecules to the NCs.

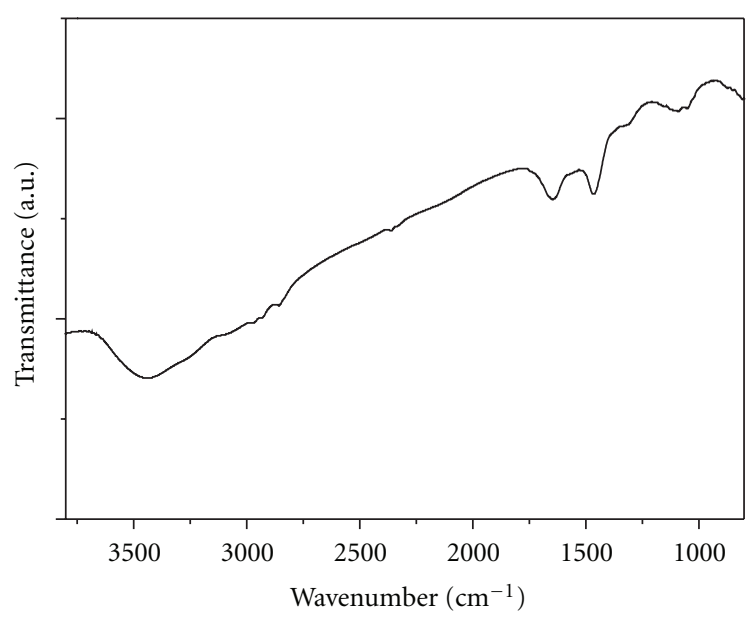

FIgURE 2: FTIR spectrum of $\mathrm{NaYF}_{4}: \mathrm{Ce}, \mathrm{Tb}, \mathrm{Gd}$ NCs.

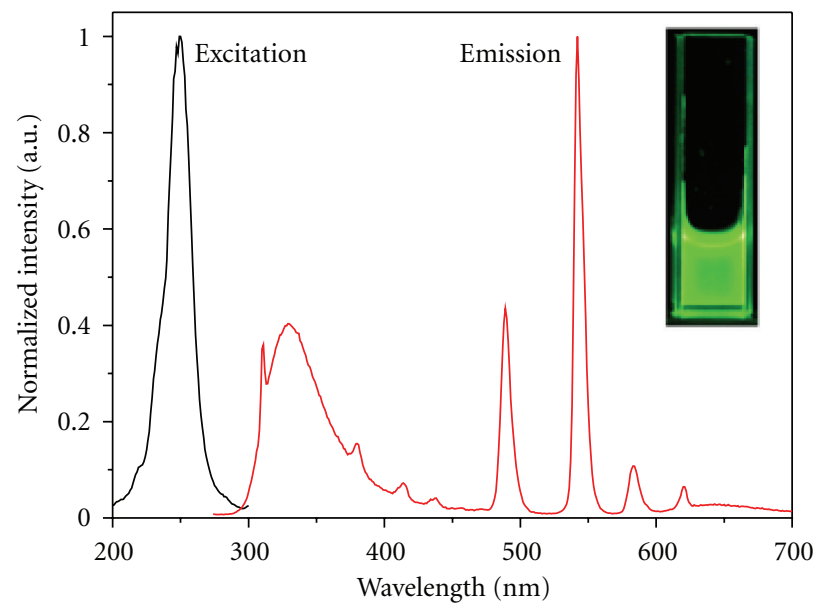

FIgURE 3: Excitation and emission spectra of the $\mathrm{NaYF}_{4}$ :Ce, $\mathrm{Tb}, \mathrm{Gd}$ NCs in water solution with concentration of $1 \mathrm{mg} / \mathrm{mL}$. The inset photograph shows the bright fluorescence of the solution under UV light irradiation.

Figure 3 showed the excitation and emission spectra of the $\mathrm{NaYF}_{4}: \mathrm{Ce}, \mathrm{Tb}, \mathrm{Gd} \mathrm{NCs}$ in water solution. In the $\mathrm{NaYF}_{4}: \mathrm{Ce}, \mathrm{Tb}, \mathrm{Gd} \mathrm{NCs}$, the $\mathrm{Ce}^{3+}$ absorbed energy effectively from ultraviolet (UV) light and transferred it to the $\mathrm{Tb}^{3+}$ that emitted green light. Under a $254 \mathrm{~nm}$ UV lamp irradiation, the particle water solution exhibited bright green emissions (Figure 2). Monitored with the emission wavelength of $542 \mathrm{~nm}$, excitation spectrum consisted of a broad and strong band with a peak at $249 \mathrm{~nm}$, which corresponded to the transitions from the ground state $2 \mathrm{~F}_{5 / 2}$ of $\mathrm{Ce}^{3+}$ to different components of the excited $\mathrm{Ce}^{3+} 5 \mathrm{~d}$ stated split by the crystal field [26]. The emission spectrum showed the characteristic and strong emission of $\mathrm{Tb}^{3+}$ with the $5 \mathrm{D}_{4}-7 \mathrm{FJ}(\mathrm{J}=6-3)$ transitions ranging from 475 to $650 \mathrm{~nm}$. A broadband $\mathrm{Ce}^{3+}$ emission (5d-4f transition) between 300 and $400 \mathrm{~nm}$, as well as a sharp line $\mathrm{Gd}^{3+}$ emission (6PJ-8S7/2 transition) at about $310 \mathrm{~nm}$, could also be observed due to incomplete energy transfer [27].

The quantum yield of the $\mathrm{NaYF}_{4}: \mathrm{Ce}, \mathrm{Tb}, \mathrm{Gd} \mathrm{NCs}$ was further determined by using quinine bisulfate in $0.5 \mathrm{M}$ $\mathrm{H}_{2} \mathrm{SO}_{4}$ as the standard samples [28]. The quantum yield was 


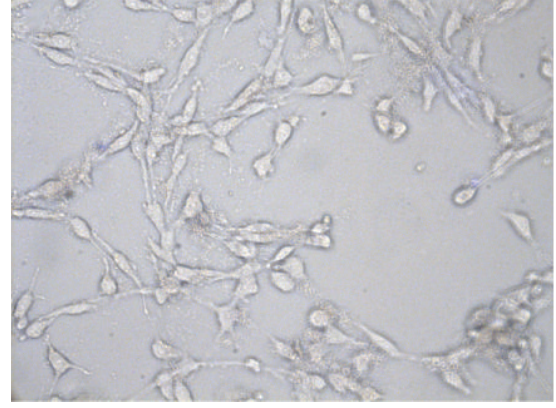

(a)

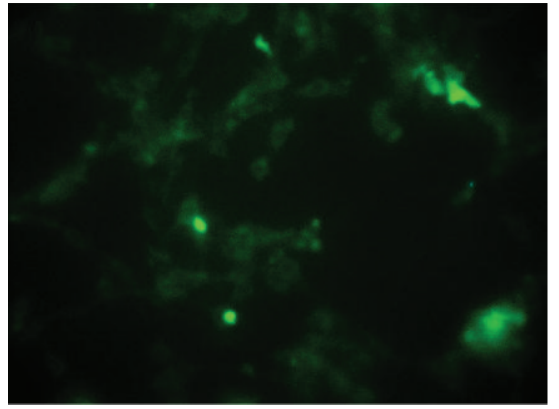

(b)

FIGURE 4: (a) Brightfield and (b) fluorescence images of C6 glioma cells incubated with folic acid coupled with NaYF 4 :Ce,Tb,Gd NCs. The fluorescence image was collected at $500-560 \mathrm{~nm}$. The scale bar is $20 \mu \mathrm{m}$.

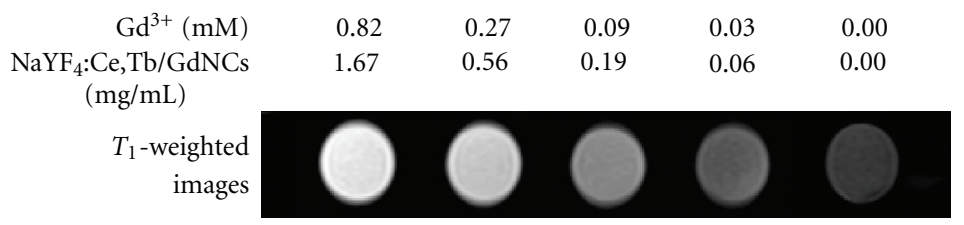

(a)

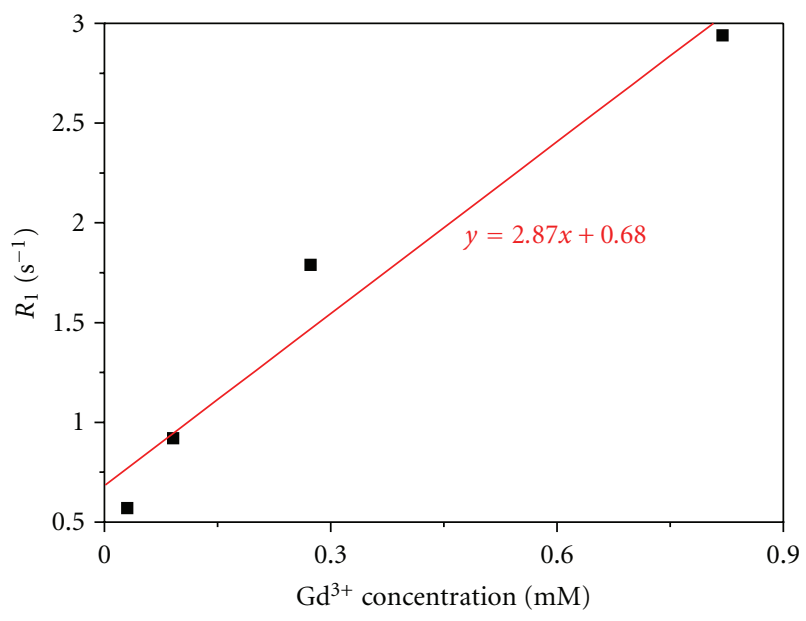

- As measured

- Linear fit

(b)

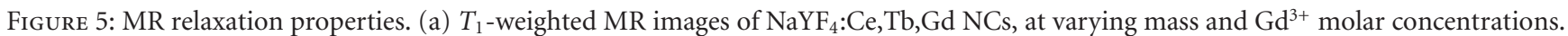
Deionized water $(0 \mathrm{mM})$ was used as the reference sample. (b) The plot of relaxation rate $\mathrm{R}_{1}$ as a function of $\mathrm{Gd}^{3+}$ concentration measured from 3T MRI scanner.

calculated from the equation $Y_{\text {sam }}=Y_{\text {sam }}\left(I_{\text {sam }} A_{\text {sta }} / I_{\text {sta }} A_{\text {sam }}\right)$, in which $A$ referred to the absorption intensity and $I$ referred to the integral fluorescence intensity. The quantum yield of quinine bisulfate was 54.6\% [29]. By measuring the luminescence of both terbium and cerium, for the $\mathrm{NaYF}_{4}: \mathrm{Ce}$, Tb,Gd NCs dispersed in water, a quantum yield of $26 \%$ was found, which was higher than that of the $\mathrm{LaF}_{3}$ :Ce,Tb NCs reported previously [30, 31].

In vitro bioimaging studies were conducted in live C6 glioma cells which were treated by folic acid conjugated with $\mathrm{NaYF}_{4}: \mathrm{Ce}, \mathrm{Tb}, \mathrm{Gd} \mathrm{NCs}$ for $12 \mathrm{~h}$. As shown in Figure 4, the comparison between fluorescence and bright field images suggested the signal distributions strongly correlated with the C6 glioma cells, proving the fine attachment of NCs on the surface of cells. No conspicuous cell death was observed, which further indicated that the NCs were not cytotoxic to the cells. The results demonstrated that the $\mathrm{NaYF}_{4}: \mathrm{Ce}, \mathrm{Tb}, \mathrm{Gd}$ NCs could be used as an efficient probe for fluorescence bioimaging.

In vitro, $T_{1}$-weighted imaging for the $\mathrm{NaYF}_{4}: \mathrm{Ce}, \mathrm{Tb}, \mathrm{Gd}$ NCs was performed with the 4 different concentrations of $\mathrm{Gd}^{3+}$ varying from 0.03 to $0.82 \mathrm{mM}$ (pure water for the background signal) on a $3 \mathrm{~T} \mathrm{MR}$ scanner. A significant dose-dependent positive enhancement was observed on MRI with 


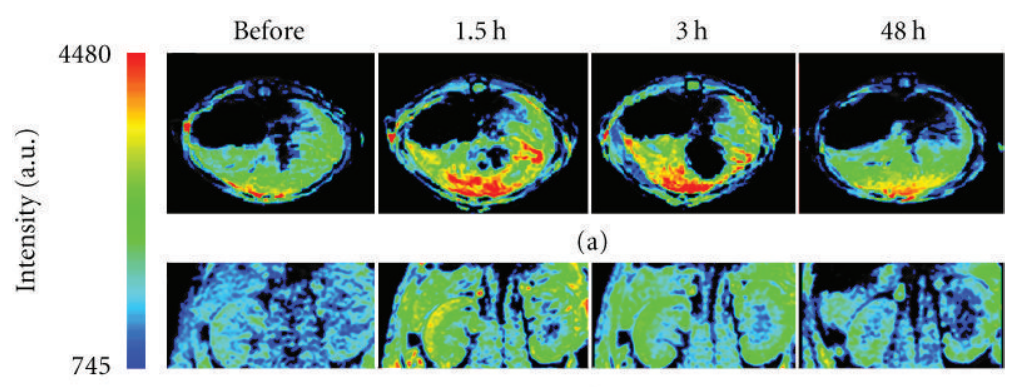

(b)

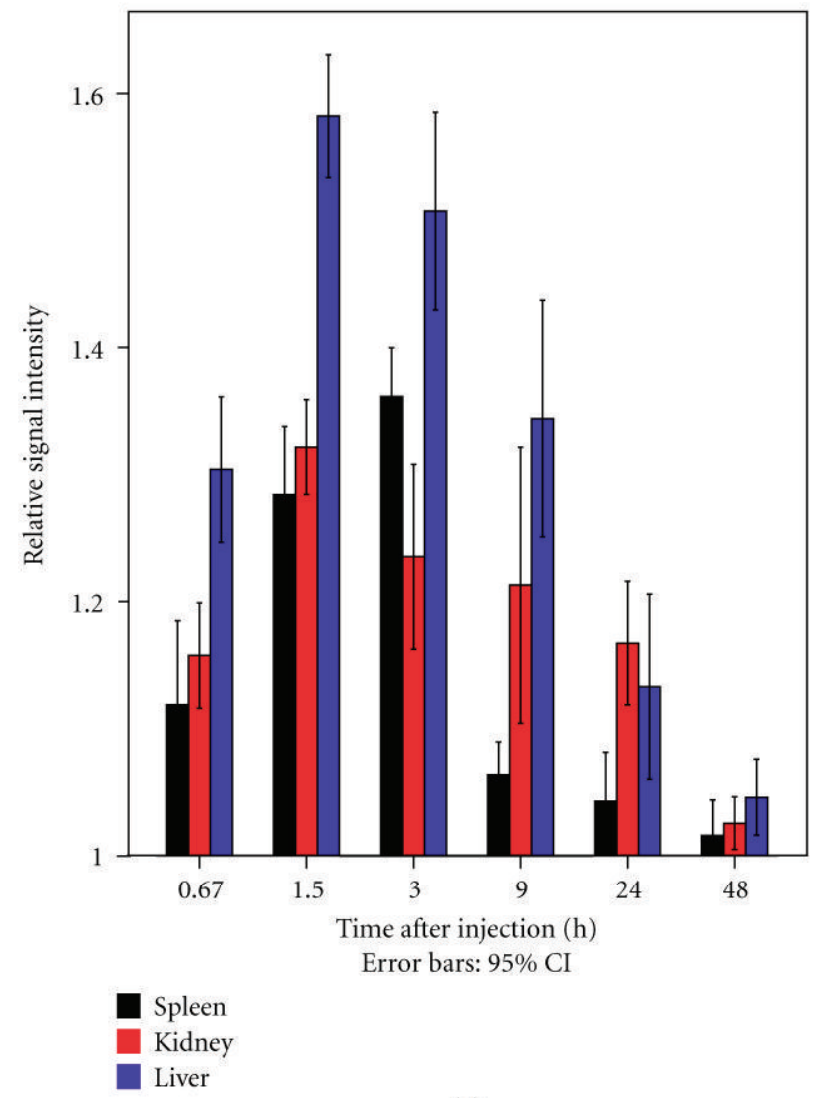

(c)

Figure 6: Series of in vivo 3D- $T_{1}$ MR images at a few representative time points of different organs in rats. On the top of arrays (a) were axial images of liver and at the bottom (b) were coronal images of spleen and kidney. (c) Mean values of relative signal intensity of different organs collected from before and after $\mathrm{NaYF}_{4}: \mathrm{Ce}, \mathrm{Tb}, \mathrm{Gd}$ NCs solution injection (rats No.-3).

increasing of $\mathrm{Gd}^{3+}$ (Figure 5(a)). The solution with maximum concentration $\left(0.82 \mathrm{mM} \mathrm{Gd}^{3+}\right)$ presented the most effective positive MR signal enhancement which is about $200 \%$. To further evaluate these properties, we calculated the MR relaxivity value $r_{1}$ of the $\mathrm{NaYF}_{4}: \mathrm{Ce}, \mathrm{Tb}, \mathrm{Gd} \mathrm{NCs}$ by fitting a linear relationship between the $R_{1}$ relaxation rates and the $\mathrm{Gd}^{3+}$ concentration (Figure 5(b)). The $r_{1}$ of $\mathrm{NaYF}_{4}: \mathrm{Ce}, \mathrm{Tb}, \mathrm{Gd} \mathrm{NCs}, 2.87 \mathrm{mM}^{-1} \mathrm{~s}^{-1}$, was higher than those of $0.14 \mathrm{mM}^{-1} \mathrm{~s}^{-1}$ of $\mathrm{NaYF}_{4}: \mathrm{Yb}, \mathrm{Er}, \mathrm{Gd} \mathrm{NCs}$ [4] and $1.4 \mathrm{mM}^{-1} \mathrm{~s}^{-1}$ of $\mathrm{NaGdF}_{4}: \mathrm{Er}, \mathrm{Yb} / \mathrm{NaGdF}_{4} \mathrm{NCs}$ [16]. Furthermore, the $r_{1}$ of our products was only slightly lower than that of commonly used Gd-DTPA $\left(3.7 \mathrm{mM}^{-1} \mathrm{~s}^{-1}\right)[32,33]$. The results suggested that the $\mathrm{NaYF}_{4}: \mathrm{Ce}, \mathrm{Tb}, \mathrm{Gd} \mathrm{NCs}$ could be a decent contrast agent for MRI application.
In vivo, MRI experiments were carried out on a Philips Achieva 3.0 T MR system. Health SD rats were injected with $\mathrm{NaYF}_{4}: \mathrm{Ce}, \mathrm{Tb}, \mathrm{Gd} \mathrm{NCs}(4.17 \mathrm{mg} / \mathrm{kg})$ through tail veins. Three-dimensional $T_{1}$-weighted images were acquired at the time points of $1.5,3$, and 48 hours after injection of the probes. Signal alteration was defined using "enhancement" (ENH) from the equation: $\mathrm{ENH}=\left(S I_{\text {pre }}-S I_{\text {post }}\right) / S I_{\text {pre }}$, according to previous studies [34]. In order to quantitatively assess the enhanced effect of NCs, Siemens Syngo software was used to measure the signal intensity of the liver, spleen, and kidney of rats. As shown in Figure 6(c), obvious enhancement of the MR signal intensity was observed within $1.5 \mathrm{~h}$ after injection. The maximum relative enhancements were $58 \%, 36 \%$, and $37 \%$ in the liver, spleen, and kidney, 
respectively. After $3 \mathrm{~h}$ after injection, the MR signal decreased gradually. After $48 \mathrm{~h}$ after injection, few probe MR signals were observed only in the intestinal tract, indicating the almost clearance of the injected probes [35]. All the treated rats had survived for more than two months without any obvious toxicity response. Considering that the injected probe dosage was much lower than conventional clinical dosage and well tolerated by the animals, the results demonstrated that the probes were effective contrast agent for noninvasive MR imaging. In clinical applications, they would show good performance in indicating organ lesions, evaluating atherosclerosis, and labeling tumors [36, 37].

\section{Conclusions}

In summary, a convenient and green route has been established for synthesizing water-soluble hexagonal-phase $\mathrm{NaYF}_{4}: \mathrm{Ce}, \mathrm{Tb}, \mathrm{Gd} \mathrm{NCs}$, which demonstrated high efficiency for both fluorescence imaging and $T_{1}$-positive contrast-enhanced MRI. Compared with previously reported bioprobes, the $\mathrm{NaYF}_{4}: \mathrm{Ce}, \mathrm{Tb}, \mathrm{Gd}$ NCs provided the dual-modality bioimaging, in which the fluorescence imaging could provide cellular- or molecular-level information with near singlemolecule sensitivity, while MRI images could provide noninvasive in vivo imaging to clearly show organ lesions. Due to the combined presence of efficient optical and MR imaging capabilities, the proposed $\mathrm{NaYF}_{4}: \mathrm{Ce}, \mathrm{Tb}, \mathrm{Gd}$ nanoprobes held great promise for simultaneous bimodal fluorescence and MR bioimaging.

\section{Acknowledgments}

The authors acknowledge financial support from the Natural Science Foundation of China (10875092, 10904119, 81030027, 30871432) and the China Postdoctoral Science Special Foundation (201003498). This work is also funded by Open Research Fund Program of the State Key Laboratory of Virology of China.

\section{References}

[1] S. A. Wickline and G. M. Lanza, "Molecular imaging, targeted therapeutics, and nanoscience," Journal of Cellular Biochemistry, vol. 87, no. 39, pp. 90-97, 2002.

[2] J. R. Heath, M. E. Phelps, and L. Hood, "NanoSystems biology," Molecular Imaging and Biology, vol. 5, no. 5, pp. 312-325, 2003.

[3] P. Prasad, Introduction to Biophotonics, John Wiley \& Sons, New York, NY, USA, 2003.

[4] R. Kumar, M. Nyk, T. Y. Ohulchanskyy, C. A. Flask, and P. N. Prasad, "Combined optical and MR bloimaging using rare earth ion doped $\mathrm{NaYF}_{4}$ nanocrystals," Advanced Functional Materials, vol. 19, no. 6, pp. 853-859, 2009.

[5] J. Michaelis, C. Hettich, J. Mlynek, and V. Sandoghdar, "Optical microscopy using a single-molecule light source," Nature, vol. 405 , no. 6784 , pp. 325-328, 2000.

[6] L. Josephson, M. F. Kircher, U. Mahmood, Y. Tang, and R. Weissleder, "Near-infrared fluorescent nanoparticles as combined MR/optical imaging probes," Bioconjugate Chemistry, vol. 13, no. 3, pp. 554-560, 2002.
[7] S. Santra, H. S. Yang, P. H. Holloway, J. T. Stanley, and R. A. Mericle, "Synthesis of water-dispersible fluorescent, radioopaque, and paramagnetic CdS: Mn/ZnS quantum dots: a multifunctional probe for bioimaging," Journal of the American Chemical Society, vol. 127, no. 6, pp. 1656-1657, 2005.

[8] Y. S. Lin, S. H. Wu, Y. Hung et al., "Multifunctional composite nanoparticles: magnetic, luminescent, and mesoporous," Chemistry of Materials, vol. 18, no. 22, pp. 5170-5172, 2006.

[9] C. L. Wu, J. Q. Hong, X. Q. Guo et al., "Fluorescent core-shell silica nanoparticles as tunable precursors: towards encoding and multifunctional nano-probes," Chemical Communications, vol. 14, no. 6, pp. 750-752, 2008.

[10] P. F. Susan, L. M. Rachel, T. F. Steven, D. Sanja, K. Nishanth, and L. Vinod, "Optical imaging and magnetic field targeting of magnetic nanoparticles in tumors," ACS Nano, vol. 4, no. 9, pp. 5217-5224, 2010.

[11] D. S. Thomas, S. Kerstin, M. I. Shukoor et al., "Highly soluble multifunctional $\mathrm{MnO}$ nanoparticles for simultaneous optical and MRI imaging and cancer treatment using photodynamic therapy," Journal of Materials Chemistry, vol. 20, no. 38, pp. 8297-8304, 2010.

[12] C. Wang, L. Cheng, and Z. Liu, "Drug delivery with upconversion nanoparticles for multi-functional targeted cancer cell imaging and therapy," Biomaterials, vol. 32, no. 4, pp. 11101120, 2011.

[13] Y. I. Park, J. H. Kim, K. T. Lee et al., "Nonblinking and nonbleaching upconverting nanoparticles as an optical imaging nanoprobe and T1 magnetic resonance imaging contrast agent," Advanced Materials, vol. 21, no. 44, pp. 4467-4471, 2009.

[14] J. Zhou, Y. Sun, X. X. Du, L. Q. Xiong, H. Hu, and F. Y. $\mathrm{Li}$, "Dual-modality in vivo imaging using rare-earth nanocrystals with near-infrared to near-infrared (NIR-to-NIR) upconversion luminescence and magnetic resonance properties," Biomaterials, vol. 31, no. 12, pp. 3287-3295, 2010.

[15] Y. C. Cao and J. H. Wang, "One-pot synthesis of highquality zinc-blende CdS nanocrystals," Journal of the American Chemical Society, vol. 126, no. 44, pp. 14336-14337, 2004.

[16] K. Kömpe, H. Borchert, J. Storz et al., "Green-emitting $\mathrm{CePO}_{4}: \mathrm{Tb} / \mathrm{LaPO}_{4}$ core-shell nanoparticles with $70 \%$ photoluminescence quantum yield," Angewandte Chemie International Edition, vol. 42, no. 44, pp. 5513-5516, 2003.

[17] J. W. Stouwdam and F. C. J. M. van Veggel, "Near-infrared emission of redispersible $\mathrm{Er}^{3+}, \mathrm{Nd}^{3+}$, and $\mathrm{Ho}^{3+}$ doped $\mathrm{LaF}_{3}$ nanoparticles," Nano Letters, vol. 2, no. 7, pp. 733-737, 2002.

[18] K. Riwotzki and M. Haase, "Wet-chemical synthesis of doped colloidal nanoparticles: $\mathrm{YVO}_{4}$ : $\mathrm{Ln}(\mathrm{Ln}=\mathrm{Eu}, \mathrm{Sm}, \mathrm{Dy})$," Journal of Physical Chemistry B, vol. 102, no. 50, pp. 10129-10135, 1998.

[19] W. Denk, J. H. Strickler, and W. W. Webb, “Two-photon laser scanning fluorescence microscopy,” Science, vol. 248, no. 4951, pp. 73-76, 1990.

[20] R. A. Niesner, V. Andresen, and M. Gunzer, "Intravital twophoton microscopy: focus on speed and time resolved imaging modalities," Immunological Reviews, vol. 221, no. 1, pp. 7-25, 2008.

[21] G. R. Choppin and K. M. Schaab, "Lanthanide(III) complexation with ligands as possible contrast enhancing agents for MRI," Inorganica Chimica Acta, vol. 252, no. 1-2, pp. 299-310, 1996.

[22] K. W. Krämer, D. Biner, G. Frei, H. U. Güdel, M. P. Hehlen, and S. R. Lüthi, "Hexagonal sodium yttrium fluoride based green and blue emitting upconversion phosphors," Chemistry of Materials, vol. 16, no. 7, pp. 1244-1251, 2004. 
[23] F. Zhang, Y. Wan, T. Yu et al., "Uniform nanostructured arrays of sodium rare-earth fluorides for highly efficient multicolor upconversion luminescence," Angewandte Chemie International Edition, vol. 46, no. 42, pp. 7976-7979, 2007.

[24] O. Ehlert, R. Thomann, M. Darbandi, and T. Nann, "A fourcolor colloidal multiplexing nanoparticle system," ACS Nano, vol. 2, no. 1, pp. 120-124, 2008.

[25] S. Liang, Y. Liu, Y. Tang et al., "A user-friendly method for synthesizing high-quality $\mathrm{NaYF}_{4}: \mathrm{Yb}, \operatorname{Er}(\mathrm{Tm})$ nanocrystals in liquid paraffin," Journal of Nanomaterials, vol. 2011, Article ID 302364, 7 pages, 2011.

[26] M. Yu, J. Lin, J. Fu, H. J. Zhang, and Y. C. Han, "Sol-gel synthesis and photoluminescent properties of $\mathrm{LaPO}_{4}: \mathrm{A}\left(\mathrm{A}=\mathrm{Eu}^{3+}\right.$, $\left.\mathrm{Ce}^{3+}, \mathrm{Tb}^{3+}\right)$ nanocrystalline thin films," Journal of Materials Chemistry, vol. 13, no. 6, pp. 1413-1419, 2003.

[27] F. Wang, X. Fan, M. Wang, and Y. Zhang, "Multicolour $\mathrm{PEI} / \mathrm{NaGdF}_{4}: \mathrm{Ce}^{3+}, \mathrm{Ln}^{3+}$ nanocrystals by single-wavelength excitation," Nanotechnology, vol. 18, no. 2, Article ID 025701, 2007.

[28] E. V. Shevchenko, D. V. Talapin, A. L. Rogach, A. Kornowski, M. Haase, and H. Weller, "Colloidal synthesis and self-assembly of CoPt3 nanocrystals," Journal of the American Chemical Society, vol. 124, no. 38, pp. 11480-11485, 2002.

[29] W. Melhuish, "Quantum efficiencies of fluorescence of organic substan ces: effect of solvent and concentration of the fluorescent solute," Journal of Physical Chemistry, vol. 65, no. 2, pp. 229-235, 1961.

[30] J. W. Stouwdam, G. A. Hebbink, J. Huskens, and F. C. J. M. Van Veggel, "Lanthanide-doped nanoparticles with excellent luminescent properties in organic media," Chemistry of Materials, vol. 15, no. 24, pp. 4604-4616, 2003.

[31] F. Wang, Y. Zhang, X. P. Fan, and M. Q. Wang, "Facile synthesis of water-soluble $\mathrm{LaF}_{3} \mathrm{Ln}^{3+}$ nanocrystals," Journal of Materials Chemistry, vol. 16, no. 11, pp. 1031-1034, 2006.

[32] R. B. Lauffer, "Paramagnetic metal complexes as water proton relaxation agents for NMR imaging: theory and design," Chemical Reviews, vol. 87, no. 5, pp. 901-927, 1987.

[33] K. M. Donahue, D. Burstein, W. J. Manning, and M. L. Gray, "Studies of Gd-DTPA relaxivity and proton exchange rates in tissue," Magnetic Resonance in Medicine, vol. 32, no. 1, pp. 6676, 1994.

[34] P. Reimer, M. Müller, C. Marx, and T. Balzer, "Evaluation of the time window for resovist enhanced T2-weighted MRI of the liver," Academic Radiology, vol. 9, no. 2, pp. S336-S338, 2002.

[35] L. Q. Xiong, T. S. Yang, Y. Yang, C. J. Xu, and F. Y. Li, "Longterm in vivo biodistribution imaging and toxicity of polyacrylic acid-coated upconversion nanophosphors," Biomaterials, vol. 31, no. 27, pp. 7078-7085, 2010.

[36] S. Valable, E. L. Barbier, M. Bernaudin et al., "In vivo MRI tracking of exogenous monocytes/macrophages targeting brain tumors in a rat model of glioma," NeuroImage, vol. 40, no. 2, pp. 973-983, 2008.

[37] V. Amirbekian, M. J. Lipinski, K. C. Briley-Saebo et al., "Detecting and assessing macrophages in vivo to evalute atherosclerosis noninvasively using molecular MRI," Proceedings of the National Academy of Sciences of the United States of America, vol. 104, no. 3, pp. 961-966, 2007. 

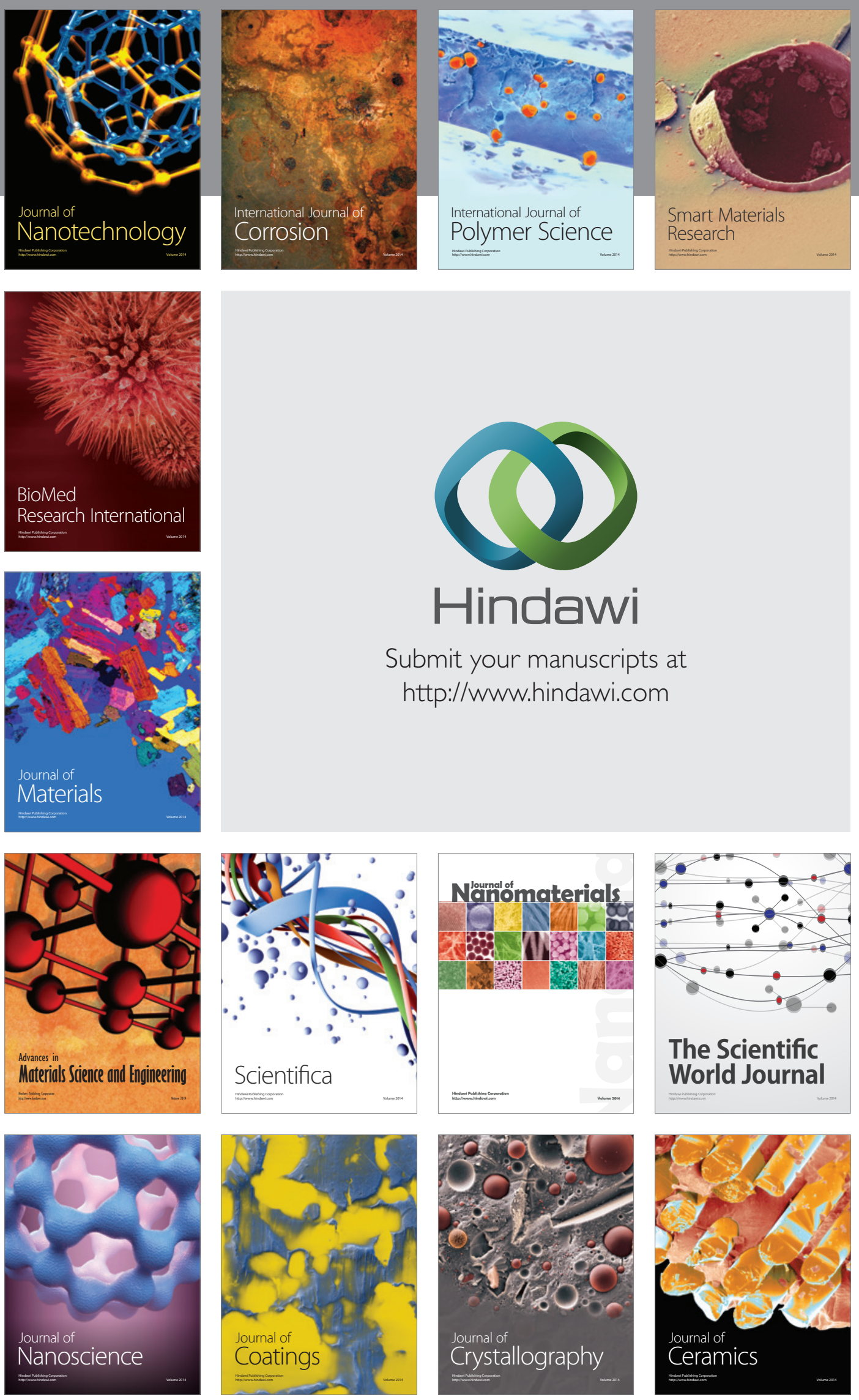

The Scientific World Journal

Submit your manuscripts at

http://www.hindawi.com

\section{World Journal}

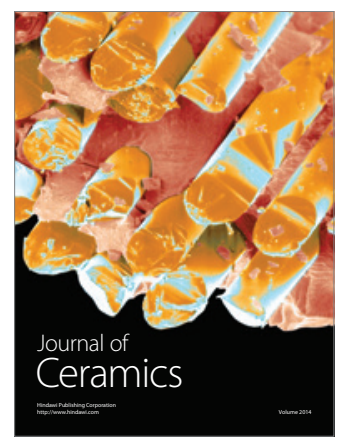

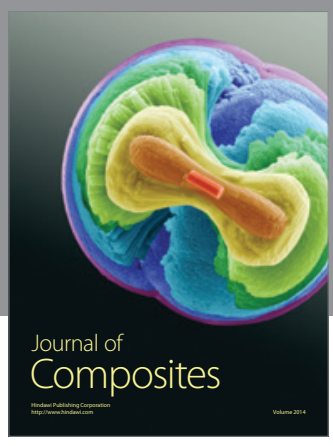
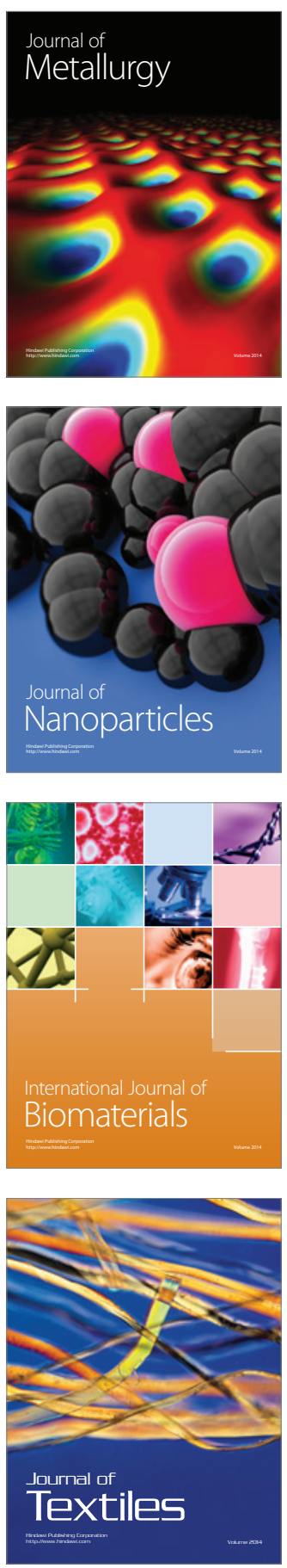